\title{
Right ventricular systolic dysfunction in patients with severe ischemic cardiomyopathy - CMR insights into an interventricular relationship
} \author{
Thomas Marwick ${ }^{4}$, Deborah Kwon ${ }^{2,3}$ \\ From 16th Annual SCMR Scientific Sessions \\ San Francisco, CA, USA. 31 January - 3 February 2013
}

Joao L Cavalcante ${ }^{1 *}$, Zoran B Popovic ${ }^{2,3}$, Rory Hachamovitch ${ }^{2}$, Milind Y Desai ${ }^{2,3}$, Scott D Flamm²,3,

\section{Background}

Right ventricular systolic dysfunction is associated with worsened outcomes and poor survival in patients with heart failure. However, it is unclear what mechanisms, other than the presence of RV infarction, contribute to the development of RV dysfunction in patients with severe ischemic cardiomyopathy. We sought to determine the impact of baseline demographic variables, CAD severity, LV diastolic function assessed by echocardiography, ventriculovascular coupling, LV remodeling, aortic biomechanical properties, and RV infarction, assessed by CMR, on $\mathrm{RV}$ ejection fraction.

\section{Methods}

Patients were selected if they had undergone TTE and CMR studies within 7 days (median $=1$ day). 354 patients with LVEF $\leq 40 \%$ and $\geq 70 \%$ stenosis in $\geq 1$ coronary artery but without prior mitral valve surgery, fused E/A waves, atrial fibrillation or $>$ moderate mitral regurgitation were included. Of those, 30 patients were excluded due to suboptimal CMR image quality for adequate RV volume tracings. A total 324 charts were reviewed for demographic and laboratorial data. Diastolic function assessment was performed as per guidelines. Aortic biomechanics were measured using previously validated software (ARTFUN, INSERM U678, Paris, France) using semi-automated tracing of aortic contours with phasecontrast images and through-plane velocity encoding of the ascending and descending aorta. CMR evaluation also included long and short axis assessment of LV/RV function respectively on balanced steady state free precession images along with assessment of LV/RV myocardial scar (on phase-sensitive inversion recovery DHE-CMR sequence $\sim 10-20$ minutes). Multivariate linear regression analysis performed to identify the independent predictors of RVEF.

\section{Results}

Males represented $73 \%$ of the cohort with a mean age of $63 \pm 11$ years. Mean LVEF was $23 \pm 9 \%$ and mean RVEF

Table 1 Multivariate predictors of right ventricular ejection fraction

\begin{tabular}{lllllll}
\hline & \multicolumn{2}{l}{ Unstandardized coefficients } & Standardized coefficients & & \multicolumn{2}{c}{$\mathbf{9 5 . 0} \%$ Confidence Interval for B } \\
\hline Linear Regression Model & B & Std error & Beta & P value & Lower bound & Upper bound \\
\hline WC & 14.8 & 2.192 & .331 & $<0.0001$ & 10.495 & 19.119 \\
LV Diastolic Dysfunction & -3.879 & .586 & -.323 & $<0.0001$ & -5.031 & -2.726 \\
RV Infact by CMR & -3.843 & 1.212 & -.146 & 0.002 & -6.228 & -1.458 \\
Gender male & 3.902 & 1.461 & .123 & .008 & 1.026 & 6.777 \\
\hline
\end{tabular}

(*) After adjusting for age, body surface area, glomerular filtration rate, hypertension, diabetes, dyslipidemia, QRS duration, ascending aorta distensibility, LV sphericity, total scar burden, coronary artery disease severity, left ventricular end-systolic volume index. VVC = ventricular-vascular coupling.

${ }^{1}$ Heart and Vascular Institute, University of Pittsburgh, Pittsburgh, P, USA

Full list of author information is available at the end of the article 
$42 \pm 14 \%$. DDFx was classified as either: stage 1 (44\%), stage $2(25 \%)$ or stage $3(31 \%)$. The independent predictors of RVEF are listed on Table 1.

\section{Conclusions}

In patients with severe ICM, impaired ventriculovascular coupling and LV diastolic function are associated with RV dysfunction, independent of the presence of RV infarction.

\section{Funding}

None.

\section{Author details}

${ }^{1}$ Heart and Vascular Institute, University of Pittsburgh, Pittsburgh, P, USA.

${ }^{2}$ Heart and Vascular Institute, Cleveland Clinic Foundation, Cleveland, $\mathrm{OH}$,

USA. ${ }^{3}$ Imaging Institute, Cleveland Clinic Foundation, Cleveland, $\mathrm{OH}, \mathrm{USA}$.

${ }^{4}$ Menzies Research Institute, University of Tasmania, Hobart, TAS, Australia.

Published: 30 January 2013

doi:10.1186/1532-429X-15-S1-P203

Cite this article as: Cavalcante et al:: Right ventricular systolic

dysfunction in patients with severe ischemic cardiomyopathy - CMR

insights into an interventricular relationship. Journal of Cardiovascular

Magnetic Resonance 2013 15(Suppl 1):P203.

Submit your next manuscript to BioMed Central and take full advantage of:

- Convenient online submission

- Thorough peer review

- No space constraints or color figure charges

- Immediate publication on acceptance

- Inclusion in PubMed, CAS, Scopus and Google Scholar

- Research which is freely available for redistribution

Submit your manuscript at www.biomedcentral.com/submit 